\title{
ESPACIOS DE EDUCACIÓN MUSICAL \\ en Quibdó (Chocó-Colombia)
}

\author{
Ana María Arango \\ CANDidata Al DOCTORADO EN ANTROPOlogía DE LA UnIVERSIDAD DE BARCELONA \\ anitaarango78@yahoo.es
}

\begin{abstract}
Resumen
PARTIR DEL EXAMEN DE LOS DIFERENTES ESCENARIOS DE APRENDIZAJE MUSICAL EN UNA SOCIEDAD, Aeste artículo analiza cómo sectores dominantes instrumentalizan la música para el adoctrinamiento y la construcción de nuevos sujetos sociales. El quehacer musical de dichos sujetos es el resultado no sólo de una serie de asimilaciones, sino también de resistencias dentro de mecanismos de aprendizaje complejos y eclécticos. En Quibdó (departamento del Chocó, Colombia), además de los espacios más visibles de educación musical, en los últimos años han surgido otros escenarios que se nutren de los anteriores pero que se caracterizan por responder a los discursos y a las dinámicas transnacionales de cooperación internacional y a los movimientos sociales. En estos espacios de educación las relaciones de poder están lejos de ser una simple historia de transmisión de conocimientos o un relato de imposiciones y asimilaciones de unos sectores sobre otros.

Palabras Clave: etnomusicología, educación musical, comunidades de práctica, afrocolombianos, cooperación internacional, Quibdó (Chocó-Colombia).
\end{abstract}

\section{Spaces of musical education in Quibdo (ChOco-Colombia)}

\begin{abstract}
THROUGH THE ANALYSIS OF DIFFERENT SCENARIOS FOR MUSICAL LEARNING IN A SOCIETY IT IS POSSIBLE TO see how music becomes an instrument used by dominant sectors for the indoctrination and construction of new social subjects. The musical life of subjects, however, is the result not only of a series of assimilations but resistances within complex and eclectic learning mechanisms. In Quibdo (Choco-Colombia), in addition to the most visible spaces for musical education, new scenarios have appeared that draw on the latter ones but are characterized by their response both to the discourses and transnational dynamics of international cooperation as well as social movements. In all these educational spaces, power relations are far from being a simple history of transmission of knowledge or a tale of impositions and assimilations from some sectors onto others.

KEY WORDS: Ethnomusicology, musical education, communities of practice, Afrocolombians, international cooperation, Quibdo (Choco-Colombia)
\end{abstract}

\section{Revista Colombiana de Antropología}

Volumen 44 (I), enero-junio 2008, pp. I57-I89 
Lo fundamental de la instrucción, de la escuela del padre Isaac Rodríguez, era enseñarnos música para servirle a Dios (...) pero todo el mundo en su mente antes de llegar al padre Isaac lo que quería era ser músico pero no para tocarle a Dios apenas, porque si le tocamos sólo a Dios, entonces, ¿cuándo le tocamos a los humanos? ${ }^{1}$.

LeOnidas ValenCIA. Maestro de música de Quibdó

\begin{abstract}
LOS africanos QUe lLegaron a los PUERTos de la Nueva Granada la esclavitud les arrebató su lengua, su cultura y su religión. En Пel Pacífico colombiano, y particularmente en el departamento del Chocó, la imposición de la doctrina católica colonial estableció una compleja maquinaria cultural mediante la cual se trató de hacer invisible el legado con el que llegaron los esclavos. La vida musical de la región es una muestra de ello. Sin embargo, la música chocoana es también la historia de la reafirmación y el eclecticismo de la población negra a la hora de asumir conocimientos y valores dentro de una formación europea y católica.
\end{abstract}

En este artículo ${ }^{2}$ me propongo explorar los principales espacios de educación musical en Quibdó -capital del departamento del Chocó- y los escenarios emergentes de aprendizaje auspiciados por la cooperación internacional. A partir de allí analizaré las complejidades que existen entre las relaciones de poder y los mecanismos de intercambio de saberes entre unos sectores "dominantes" y otros "subalternos". El texto tiene como objeto examinar las relaciones complejas que se dan en comunidades de práctica que se transforman, se comunican y se consolidan

I. Todas las entrevistas citadas fueron hechas en Quibdó entre el I6 de septiembre y el 5 de octubre de 2006, durante las fiestas de san Francisco de Asís, conocidas como las fiestas de san Pacho.

2. Este artículo da cuenta de los resultados de la primera parte de investigación de la tesis doctoral en antropología social en la Universidad de Barcelona, cuyo objetivo es el estudio de las comunidades de práctica en la educación musical en Quibdó. Así, el texto es una síntesis del trabajo final del DEA. Agradezco la información y el apoyo brindado por el maestro Leonidas Valencia, en Quibdó, y la orientación de Manuel Delgado y Carlos Miñana. la etnomusicología, en la comprensión de los procesos de aprendizaje musical y las relaciones niño-adulto, naturaleza-cultura, valores impuestos por unos sectores hegemónicos. Por otra parte, partiendo del planteamiento de Carlos Miñana sobre el conocimiento musical y sus modos de transmisión en las comunidades indígenas del departamento del Cauca, cuestiono la visión dualista que subyace en las ciencias sociales en general, y específicamente en más allá de las doctrinas y los .

.


individuo-sociedad. Antes de abordar los diferentes espacios de educación musical en Quibdo, esbozaré las perspectivas teóricas que desde la etnomusicología han explorado la transmisión de conocimientos y expondré los puntos de partida que me brindan herramientas para pensar y definir dichos espacios.

\section{Perspectivas teóricas}

N LA ETNOMUSICOLOGÍA EL ESTUDIO DE LA EDUCACIÓN MUSICAL HA ESTADO -mediado por concepciones propias de las ciencias sociales sobre el aprendizaje y la niñez (Minks, 2002:380). Durante el siglo diecinueve y la primera mitad del veinte la musicología comparada se acercó a las culturas musicales desde la óptica del difusionismo y el evolucionismo ${ }^{3}$. Estas corrientes teóricas compartían la idea de que el sistema musical occidental era superior a los demás y establecieron analogías entre la música infantil y la música "primitiva” (Minks, 2002: 382). El siguiente paradigma que influyó en la comprensión de la educación musical fue el de la enculturación, que se enfoca en el análisis de los procesos de socialización de normas culturales y musicales (Blacking, I973; Merriam, I964; Nettl y Béhague, I973). La investigación de John Blacking sobre los venda -probablemente la más representativa de esta perspectiva- revalúa la mirada etnocéntrica de investigaciones anteriores y plantea que las canciones infantiles cristalizan normas de comportamiento y son un complejo mundo de aprendizaje sobre el universo musical y la vida social (Blaking, I967) ${ }^{4}$. A esta perspectiva se contrapone la de la autonomía cultural (Kartomi, I980, I99I), que parte de la idea de que además de ser autónoma, universal y homogénea, la música infantil presenta valores sociales y culturales propios aparte de los procesos de socialización (Minks, 2002: 392).

De otra parte, con base en la antropología cognitiva se han de-

3. Bruno Nettl se ha encargado de definir la musicología comparada y sus transformaciones para convertirla en etnomusicología, junto con las nuevas tendencias de esta última $(1983,2004)$. En general, la etnomusicología se define como el estudio de la música en la cultura o como cultura (Merriam, 1964). Desde la perspectiva de esta investigación, la etnomusicología se entiende como el estudio de la vida musical de un pueblo.

4. Blacking estudió a los venda-ubicados actualmente en Sudáfrica-, cuya familia lingüística es la bantú, cuando aún tenían un territorio autónomo. sarrollado algunas ideas novedosas para la etnomusicología que aportan una perspectiva cultural relacionada con los procesos y los patrones de aprendizaje. A partir del 
planteamiento de Vygotsky, uno de los principales exponentes del cognitivismo, se plantea el conocimiento como una cuestión social y no sólo mental e individual. Vygotsky considera la cognición y las acciones humanas como un proceso de comunidades de aprendizaje (Minks, 2002; Rogoff, 1989), como parte de la participación en comunidades de práctica (Lave y Wenger, I99I) y como una acción mediada que está situada socialmente (Wertsch, I99I).

Las investigaciones etnográficas han sido fundamentales también en los estudios de la educación musical (Marsh, 1995; Campbell, 1998), en tanto exploran y validan los contextos informales de aprendizaje y se preguntan cómo los niños -junto con sus pares- aprenden viendo, escuchando e imitando. La etnografía y sobre todo la observación participante permiten llegar a la cotidianidad de estos procesos. Existe así mismo una serie de estudios que más que emplear el método etnográfico se enfocan en el discurso de la letra de las canciones. Ana M. Fernández Poncela señala que "los textos constituyen un intercambio de sentido. De ahí que más allá del intercambio lingüístico, tiene lugar una interacción social. Las canciones son un texto, son palabras y son un acto social. Sus mensajes son parte de la construcción del mundo y la construcción y autoconstrucción de sujetos sociales" (2005: 29). Desde esta perspectiva, la canción legitima formas de ser en un lenguaje orientador, regulador, transformador y transmisor. Sin embargo, la mayoría de las veces los estudios etnográficos y los de análisis de discurso reproducen el paradigma de la enculturación y la socialización que analizan su objeto de estudio con la idea de que hay un repertorio que se transmite de un sector a otro, de unos adultos a unos niños, de un sector hegemónico a uno subalterno, de un sector letrado a uno iletrado, etcétera. En este artículo planteo mi rechazo a la idea de una "cultura" que se transmite a un colectivo pasivo que la recibe y la asimila, y a la de una niñez universal y homogénea que tiene sus códigos en la reproducción de un repertorio propio y autónomo (Kartomi, I99I).

La enculturación y la autonomía cultural parten de una visión dualista entre creación/reproducción, individuo/sociedad y naturaleza/cultura. Como señala Miñana, en la antropología

5. Según Miñana, perspectivas como las de Alan Merriam basadas en la idea de la música como cultura que transmite unos órdenes sonoros, comportamientos y conceptos (Merriam, I973) dan cuenta de una visión funcionalista (2005: 3-IO). de la música ha prevalecido el enfoque funcionalista (2005: 13$)^{5}$ que se basa en el paradigma de la socialización y que presenta las siguientes características: I) 
dualismo: naturaleza/cultura, individuo/sociedad; 2) existencia de un orden social predeterminado al que los individuos se adaptan o de lo contrario se convierten en seres desarraigados, inadaptados, anómalos, anormales o desviados; 3) idea de progreso y desarrollo vinculada con las ideas evolucionistas -muy ligada con el proceso laico que busca la salvación mediante la educación-; 4) mito freudiano del peso determinista de la primera infancia en la vida adulta; 5) primacía de los padres y los adultos en los procesos de socialización frente a la capacidad de actuación de los niños mismos (Ibídem, 2005: 3-IO). La crítica de Miñana parte de la propuesta teórica de Tim Ingold (I986), según la cual no existe una entidad suprema llamada "sociedad" ni una especie de juego denominado "cultura", sino una "vida social" que responde a un proceso en el que los sujetos interactúan por medio de la cultura como instrumento. En este sentido, Miñana sostiene que un repertorio musical se aprende en medio de un acontecer, no es algo que se adquiere o que ya está hecho. La música es "algo que se logra en forma activa y creativa ('poniendo el oído') observando ('entre las piernas de los mayores'...)" (2005: 12).

Más allá de la socialización de un sistema o de una estructura cultural y musical o de la existencia autónoma a priori de estas en mundos infantiles o subalternos, lo que tenemos es una serie de prácticas que se consolidan en el acontecer de "la vida social". Los repertorios, estilos, formatos $\mathrm{y}$ usos del quehacer musical de un grupo social se refuerzan mediante comunidades de práctica ${ }^{6}$ que pueden pertenecer o no a contextos de educación formal ${ }^{7}$. Cuando vemos la importancia de la educación musical en la construcción de sujetos sociales abrimos nuevos caminos para cuestionar no sólo los contenidos educativos, sino los mecanismos y las estrategias mediante las cuales se legitiman unas formas de saber y aprendizaje sobre otras ${ }^{8}$. Partiendo de la propuesta de Carlos Miñana veremos cómo:

6. Las comunidades de práctica son grupos que se constituyen gracias a que comparten procesos de aprendizaje alrededor de un compromiso mutuo, una empresa compartida y un repertorio común (Wenger, 200I: I26).

7. Entiendo la educación formal como aquella que da cuenta de los aspectos académicos o laborales sujetos al sistema de niveles y grados establecidos por la ley de una nación; y la educación informal como cualquier conocimiento adquirido por fuera de dichos niveles y mecanismos de legitimación.

8. Parto aquí de una visión foucaultiana del sujeto. Es decir, me refiero a ese individuo que mediante una serie de dispositivos y ejercicios de poder es "sujetado" y se "sujeta" a sí mismo, a unas formas específicas de ser y existir. Para Foucault "hay dos significados de la palabra sujeto; sujeto a otro por control y dependencia y sujeto como constreñido a su propia identidad, a la conciencia y a su propio autoconocimiento. Ambos significados sugieren una forma de poder que sojuzga y constituye al sujeto" (Foucault, I983: 2). 
la enseñanza y el aprendizaje tienen que ver no tanto con la 'transmisión o adquisición de la cultura' o de esquemas, o de reglas, sino con la adquisición de habilidades por compromiso (...). La cultura y la sociedad no son esencias preexistentes y la educación o la enculturación ya no pueden seguirse pensando como un proceso por el que habilidades, valores e identidades propias de una cultura se introyectan en las cabezas o se tatúan en los cuerpos de los aprendices (Miñana, 2005: 16) ${ }^{9}$.

A continuación y antes de analizar los mecanismos y las formas como se configuran las comunidades de práctica en los espacios de aprendizaje en Quibdó, veremos las características de estas comunidades, sus formatos instrumentales y sus repertorios.

\section{LA VIDA MUSICAL EN EL PACÍfico}

$\bigwedge \begin{aligned} & \text { Ás QUE DE UNA “CULTURA MUSICAL”, EN EL PACíFICO HABLAMOS DE UNA } \\ & \text { "vida musical” que se transforma y se negocia permanente- } \\ & \text { mente en comunidades de práctica. Las poblaciones negras }\end{aligned}$ introducidas como esclavos durante la colonia para trabajar en las minas, asentadas luego en el litoral Pacífico colombiano, recrearon los instrumentos musicales africanos con materias primas del nuevo entorno: instrumentos como los tambores cónicos -cununos-, la marímbula, la marimba y diferentes semilleros como los guasás. En el sur del litoral Pacífico colombiano con estos instrumentos se reproduce el baile de marimba o currulao en el que se interpretan aires o géneros como la juga -deforma-

9. Esta posición de Miñana se basa en el planteamiento de Tim Ingold según el cual la cultura no es un sistema o una estructura ajena a los sujetos; es un conjunto de herramientas con las cuales las personas asumen los procesos cotidianos de la vida social (Ingold, I986).

Io. Según List, los participantes del gualí interpretan cantos de juego, romances y décimas junto con instrumentos musicales. Para este autor, es interesante que en esta región, por ejemplo, la canción de juego El folrón es interpretada tanto por los niños en sus juegos, como por los adultos en los velorios de niño. Además, el modo en que esta canción se interpreta, es el mismo dentro de los dos contextos y el mismo de la costa Atlántica (List, I989: 578). ción de la palabra "fuga", género musical europeo-, el patacoré, el bambuco viejo, el berejú y el pango, entre otros. En el contexto funerario se cantan los alabaos para velorio de adulto y los novenarios y el chigualo para el velorio de niño ${ }^{10}$, y además se encuentran unos cantos especiales llamados arrullos para los "velorios" de santos. En el Pacífico sur los elementos hispánicos son menos evidentes que en el 
Chocó, aunque en el ámbito religioso existe una alta presencia de caracteres españoles (Bermúdez, I986: II7). Los diferentes formatos instrumentales que existen responden a relaciones jerárquicas y señalan la legitimación de unos instrumentos sobre otros en la construcción de "identidades musicales"11.

Los versos en el Chocó y en el sur tienen las mismas características estructurales y temáticas: presentan arcaísmos poéticos hispánicos, especialmente del romance y la décima. Los textos de las canciones que interpreta el conjunto de marimba son por lo general versos octosílabos que se cantan intercalados con los estribillos (Bermúdez, I986: II9). Según List, en esta zona se conservan textos de canciones que hasta hace muy poco, o tal vez todavía, se pueden hallar en algunas zonas de España (I989: 584).

Los procesos de colonización en el Chocó y su fuerte conexión con la costa Caribe por el río Atrato promovieron nuevos formatos instrumentales que se fundieron con los repertorios y la memoria musical de libres y esclavos. Así, los conjuntos de instrumentos legitiman unas estéticas y unos valores sonoros y, con ellos, unas maneras de ser y de estar en el mundo. En el Chocó, el conjunto de chirimía es el más representativo y está integrado por redoblante -o caja-, bombo y platillos en la percusión, y por clarinetes, fliscornos o bombardinos y saxofones en los vientos (véase la foto I) ${ }^{12}$.

El conjunto instrumental de "chirimía clásica” se caracterizaba por interpretar géneros populares y géneros de baile de salón que estuvieron de moda en los países europeos y sus colonias durante los siglos diecio-

II. Las relaciones entre identidad y música son complejas. La identidad, como señala Peter Wade, es una idea o sensación que esconde en su definición una complejidad múltiple. La identidad es "situacional", no es constante y se construye a partir de la diferencia en cada acto de representación de los sujetos o de las poblaciones en su vida cotidiana (Wade, 2002: 256). Las prácticas y los repertorios musicales pueden ser herramientas muy efectivas para construir identidades nacionales, étnicas, raciales, de clase, de edad, de género, etcétera. En la música, y sobre todo en las músicas "populares tradicionales", el problema de los orígenes está siempre presente. En este sentido, muchos significados entran a negociarse y muchos sentimientos entran a reivindicarse por medio de la música y los discursos que se tejen en torno a ella.

I2. Anteriormente, el clarinete no estaba tan presente y a cambio se interpretaban una flauta traversa de seis orificios -metálica o de caña-y flautas con aeroducto interno de cuatro orificios que cumplían el rol del bombardino (Bermúdez, I986: II5). cho y diecinueve: jotas, polkas, mazurcas, contradanzas y pasillos. Dichos géneros, en diferentes formatos instrumentales como el conjunto de cuerdas, la timba, la banda o la chirimía, son supervivencias españolas que llegaron por el río Atrato desde el Caribe y conviven con otros géneros 


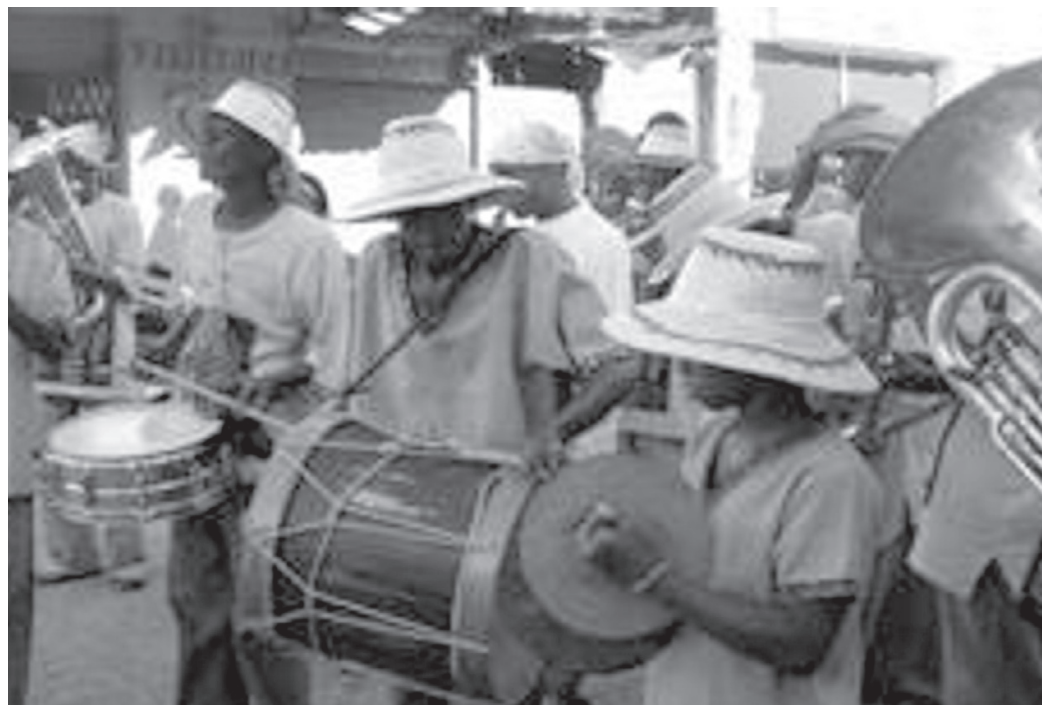

musicales en los cuales los elementos africanos e indígenas se mezclan en mayor o menor medida con el legado colonial: el currulao, el abozao, el saporrondón, el berejú, el aguabajo, etcétera. A finales del siglo veinte se desarrollaron nuevas propuestas instrumentales y estilísticas en la chirimía con la incorporación del saxofón alto y el saxofón tenor, y la amplificación del sonido que permitió más presencia de las voces en el repertorio de dicho formato ${ }^{13}$.

I3. Antes de la incorporación a la chirimía, el repertorio cantado se mantuvo sobre todo en el sexteto; este formato consiste en un pequeño bongó, guitarra, dulzaina o flauta y campana -o botella-. Además de la chirimía y el sexteto, encontramos en el Chocó otros formatos como banda: clarinetes, saxofones, trompetas, bugles, flautas, bombardinos, trombones, tubas, bombo, redoblante y platillos; conjunto: bongó, tambora, flauta de carrizo; combo: tambora, redoblante, platillos, bombardino, clarinete y saxofones; dúo o trío: guitarras y maracas; bunde: tambora, carangano, guasá, maracas, guitarras, tambora; y timba: guitarra, bongó, maracas, clave, guitarras, tambora, carangano y guasás.
Los instrumentos de la banda militar europea son fundamentales en la configuración de la música chocoana. Esta característica la comparte el Chocó con otras regiones de Colombia -las sabanas de Córdoba, Sucre, Cesar y Magdalena- y del mundo -ex colonias europeas en África, América y Asia- en donde hay un fuerte arraigo de estos instrumentos (Béhague, 
I999; Nketia, I99I). El conjunto de chirimía responde en gran parte a la implantación de repertorios mediante la banda de guerra -con todas sus transformaciones técnicas y estéticas-y al repertorio proveniente de las misiones católicas que tuvieron un impacto significativo en esta región. En los formatos de banda y chirimía se rememora una historia de intercambios, imposiciones y adaptaciones de la comunidad negra al mundo europeo y sus instituciones religiosas, económicas y sociales. Así, la educación musical configura una de las formas más sutiles de "institucionalización” de unos valores éticos y estéticos dentro de una población muy señalada, explotada y estigmatizada como la afrocolombiana ${ }^{14}$.
I4. La raza, el mestizaje y la discriminación marcan profundamente la estructura social y económica del Chocó. La esclavitud, el sometimiento y los estereotipos negativos dentro del imaginario nacional han hecho del mestizaje una estrategia de "blanqueamiento" de lo "negro", lo "impuro" y lo "primitivo". Al igual que el mestizaje, la educación fue también para muchos de los habitantes del Chocó una estrategia de integración y ascenso social. El discurso de la identidad nacional colombiana estuvo marcado durante más de cien años por la exaltación de los valores mestizos. En la medida en que los habitantes del país se "mestizaban" existía mayor posibilidad de ser una nación desarrollada y moderna mediante el mundo de las letras. Por otra parte, ser negro, zambo o mulato implicaba ser la piedra en el zapato de un país que buscaba el progreso, la ilustración y la razón. En este sentido, la educación fue uno de los mecanismos para ascender socialmente a pesar del color de la piel. Para Wade: "la nación colombiana se alimenta de los diferentes poderes atribuidos y reclamados por cada ámbito racial: los negros y los indígenas pueden tratar de nutrirse de la riqueza y el poder político de los blancos, de su educación y su 'civilización' y, en efecto de su verdadera blancura, mientras escapan de los peldaños más bajos de la jerarquía al blanquearse a sí mismos a través del mestizaje" (1997: 56).

\section{Espacios de EDUCACIÓN MUSICAL EN QuibDó}

El gran juego de la historia es quién se amparará de las reglas, quien ocupará la plaza de aquellos que las utilizan, quién se disfrazará para pervertirlas, utilizarlas a contrapelo, y utilizarlas contra aquellos que las habían impuesto; quién introduciéndose en el complejo aparato lo hará funcionar de tal modo que los dominadores se encontrarán dominados por sus propias reglas.

Michel Foucault. I979. Genealogía del poder: I8.

A VIDA MUSICAL DE QUIBDÓ ES PARTICULAR EN RELACIÓN CON OTROS MUNICIpios del Pacífico porque los espacios de educación musical están -marcados por la fuerza de la empresa misionera, las oleadas de colonización de diversas procedencias, los altibajos económicos y las facilidades de contacto con el Caribe (González, 2003: III). 
El trabajo etnográfico y las entrevistas que tuve con los músicos de Quibdó examinan los comportamientos, los hábitos, las metodologías y los discursos que existen en las comunidades de

I5. En su investigación sobre las diferentes ideologías y metodologías que han acompañado la educación musical en las iglesias o en espacios seculares, Gordon Cox plantea que existen dos retos para los historiadores de la infancia: estudiar cómo dichas metodologías e ideologías han cambiado a lo largo del tiempo y sacar a la luz materiales sobre infancias pasadas, ya que los niños dejan pocos documentos (Cox, 2006: 3). práctica de los espacios de educación musical ${ }^{15}$. Veremos de qué manera entre sectores sociales y sujetos se tejen unas relaciones de poder y cómo dichas dinámicas de poder trascienden las lógicas de dominación porque la adquisición del conocimiento es espontánea, irreverente y ecléctica.

\section{Escuela de música de la Catedral}

LA LLEGADA DE LOS CLARETIANOS A QUIBDÓ EN I9O9 SIGNIFICÓ EL COMIENZO de una nueva etapa en la educación de la población, y la música fue una de las principales herramientas de adoctrinamiento. El sacerdote español Isaac Rodríguez llegó a Quibdó en I935 e hizo de la educación musical un eje fundamental de la misión evangeli-

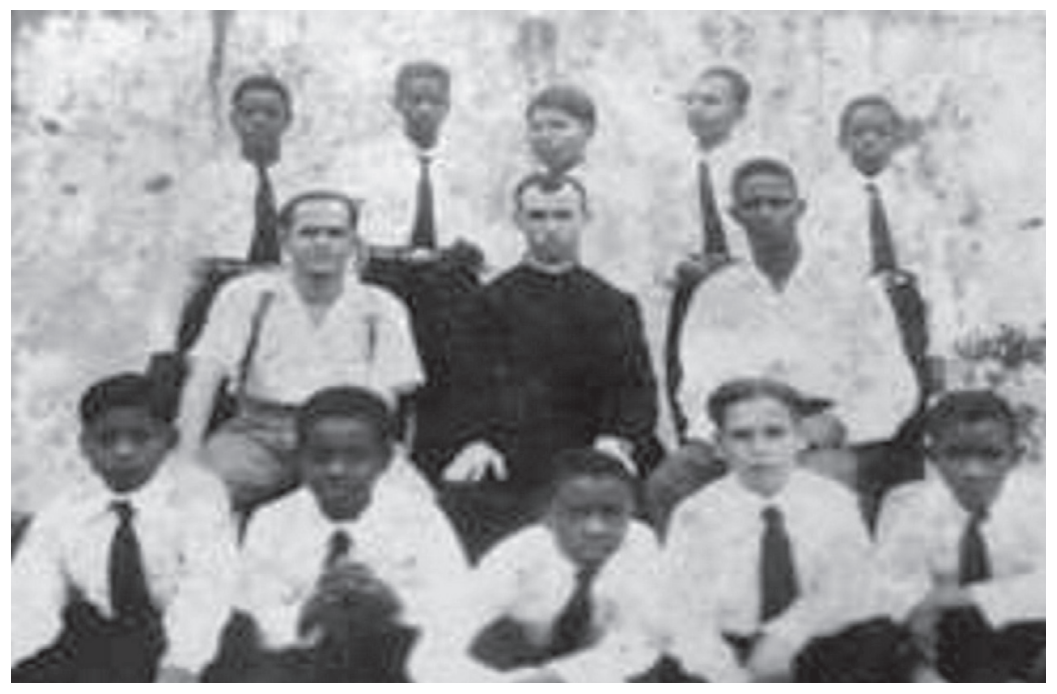

El padre Isaac Rodríguez con sus alumnos. Archivo del Centro Mama U. 
zadora de la congregación. Las crónicas de sus alumnos dejan ver fuertes sentimientos frente a él: se le venera como a un "padre" o a un "santo" a pesar de sus incontables castigos y prohibiciones en el proceso de enseñanza. Isaac Rodríguez se desempeñó como maestro de capilla y enseñó a sus alumnos el canto llano y polifónico oficial de todas las catedrales de América latina y España desde la contrarreforma (Bermúdez, 2000: I4). El método del Conservatorio de Madrid fue el utilizado en la escuela de la catedral para aprender solfeo e interpretación. Los niños del coro y de la banda debían hacer sus interpretaciones solamente para "Dios". El sacerdote rechazó explícitamente muchas veces la chirimía y la música popular, hasta el punto de llegar a satanizarla. Como lo narra Octavio Panesso, músico, compositor y ex alumno del padre Isaac:

Una vez le presentaron una partitura de Richie Ray. Él detestaba la música popular y le dijeron -Padre, tenemos un problemita aquí con esta música, con esta partitura que es de una iglesia [...] a ver si usted en su piano nos colabora un poquito con ella-. Y él metió la partitura y llegó un momento en que la estaba tocando y ya empezó como a moverse así, con los mismos ritmos, porque él sentía la música. Y cuándo percibió y comenzó a moverse demasiado dijo: -Esta es música del diablo, esta es música del demonio. Una música tan linda, tan bonita que uno les enseña, sin embargo la obra que llevan a la calle lo que les queda es pura porquería, es puro diablo, puro demonio.

Los métodos y las estrategias del padre Isaac en el desarrollo de una cultura musical y a la vez una doctrina religiosa se resumen en los siguientes puntos: I) priorización de la lecto-escritura en el proceso de aprendizaje; 2) la voz como elemento imprescindible para poseer talento musical; 3) exigencia en la pronunciación de las canciones, y 4) poca flexibilidad en las rutas de aprendizaje ${ }^{16}$. Este tipo de escuela musical no es exclusiva de Quibdó: todos los centros coloniales en los cinco continentes en los cuales se han impuesto la religión católica y protestante tienen una historia musical muy similar: prioriza-

I6. Los alumnos debían aprender primero a leer y escribir y después de demostrar ser buenos cantantes debían pasar por el aprendizaje de la tuba, para luego poder interpretar otro tipo de instrumentos. Agradezco a César Valencia y a Leonidas Valencia por esta información. Entrevistas el I6 y I9 de septiembre de 2006. ción de unos valores éticos y estéticos europeos, exclusión o "satanización” de las expresiones propias, utilización de nuevos 
instrumentos y nuevos repertorios, colonización de unos espacios mediante el uso de ellos con la música y legitimación de unos métodos y unas estrategias pedagógicas sobre otras en la institucionalización de un canon que "se lee y se escribe"17.

\section{La banda de San Francisco de Asís}

ESTA BANDA FUE Y SIGUE SIENDO UN ESPACIO PRIVILEGIADO AL CUAL ACCEDEN unos pocos músicos por sus capacidades musicales y su estatus social. Su función es acompañar las ceremonias y festividades civiles y religiosas del municipio. Como icono social, político y religioso de Quibdó, en ella se resumen las tensiones y luchas por la legitimación de géneros y repertorios musicales. Quienes pertenecen a la banda suelen sentir cierta superioridad frente a quienes no, lo cual no necesariamente responde a

I7. Para ampliar el asunto de la educación musical y los discursos sobre la infancia que se han dado en los países europeos y sus colonias desde la edad media hasta el presente es interesante ver la investigación de John Cox, quien analiza los discursos que subyacen a las políticas de la educación en el Reino Unido pero también extiende su visión a la tradición católica y a su repercusión en las mentes y los cuerpos de sus colonias (Cox, 2006).

I8. Neivo Moreno es un reconocido compositor, arreglista, investigador, intérprete y director de orquesta y grupos tradicionales. los modos interpretativos de esta se transformaron. En palabras de Leonidas Valencia:

Cuando el director de la banda muere asume la dirección Neivo. Entonces ahí sí se abrió la banda. Ya nosotros no tocamos repertorio canónico ni anticuado, nos metemos con el pueblo. Cuando uno recibe una instrucción o formación musical es para trabajarla con el pueblo. De lo contrario no tiene ningún sentido. Como encerrarme yo a aprenderme una obra de Mozart a ensayar violín por allá en un cuarto y después nunca el pueblo la conoció. Eso no tiene ningún sentido (...) la banda se untó de pueblo (...). Entonces la banda ya deja de ser una banda tan elitista (...) ahora nuestro repertorio está más enfocado a educar al pueblo. 
La transformación que llevó a cabo Neivo de Jesús Moreno buscaba la legitimación de unos géneros locales representativos y trajo como consecuencia la inserción en la banda de un repertorio de pasillos, polkas, porro chocoano, tamboritos, etcétera, propios de chirimía. Este hecho significó la apertura de la banda "al pueblo". De esta manera, la banda de San Francisco de Asís configura un espacio fundamental en el que se negocian nuevos valores en torno a los métodos y contenidos de la enseñanza musical local.

\section{Espacios domésticos: la familia y el barrio}

EL ENTORNO FAMILIAR Y EL ENTORNO BARRIAL -LAS CASAS Y LAS CALLES - SON espacios fundamentales de aprendizaje musical. De hecho, los músicos entrevistados coinciden en afirmar que su iniciación se llevó a cabo en estos espacios y no en la escuela de la catedral. Las fronteras entre lo público y lo privado en las zonas residenciales de Quibdó y del Chocó en general son difusas; los vecinos se integran como familias y el barrio es un referente fundamental que define a las personas. Los formatos que circulan en estos medios musicales se caracterizan por ser abiertos. Es decir, nos encontramos con la chirimía pero también con el sexteto acompañado de violines, dulzainas o flautas.

Las tradiciones familiares son claves en el aprendizaje de técnicas y repertorios musicales. Cada familia tiene su sello: su repertorio, su estilo específico de interpretación, su reconocimiento en uno o varios instrumentos, sus escenarios, sus historias y anécdotas, sus valores y sus comportamientos. Pero en las tradiciones musicales "académicas" de muchas partes del mundo -sobre todo del mundo occidental- este tipo de escuelas son invisibles y difícilmente reconocidas. Su carácter informal le arrebata cierta "legitimidad" frente a otros espacios institucionales o “rituales”. En el ámbito doméstico los niños tienen la libertad de organizarse, de elegir a sus pares y de emprender roles y competencias. Cuando hay un adulto las cosas marchan de forma diferente porque de alguna manera sienten que deben seguir sus instrucciones. Como adultos nos olvidamos que ellos construyen por sí solos sus espacios musicales, con repertorios y competencias que están en juego y que pueden tener un valor 
simbólico igual o incluso mayor que el que experimentan en otros contextos de educación formal.

En el Chocó, como en el resto del Pacífico y en la mayoría de las culturas musicales tradicionales, las fronteras entre intérprete y público son difusas (Nettl, 1973). La figura del "genio musical" -como define Blacking este fenómeno tan occidental de reconocer el talento musical sólo en unos pocos- es borrosa y poco tangible porque los oyentes tienen una amplia participación dentro de los performance (Blacking, I973: 22). Así, en los ambientes domésticos -a pesar de que hay "figuras" reconocidas- el "público" participa con la interpretación de instrumentos y con el canto y la exigencia hacia los músicos es mucho mayor. Si un músico logra mantener el "monopolio" sobre la interpretación de un instrumento es porque se trata de una persona realmente virtuosa.

Es muy común que en los espacios familiares y barriales no se reconozca ningún tipo de "metodología" de aprendizaje. Además de la falta de reconocimiento de estos lugares como "escuelas de música”, los mecanismos pedagógicos internos se vuelven invisibles también, porque se aprende haciendo. Mirar atentamente al músico preferido es el primer paso: niños que apenas saben caminar observan con cuidado cada movimiento de manos en los instrumentos, y después, una vez las manos logran soportar el peso de los platillos, del bombo o de un instrumento de viento, hay que lanzarse a tocar. En su investigación sobre las rutas de aprendizaje de las chirimías indígenas del Cauca, Carlos Miñana (2005) plantea que allí la mejor posición para el aprendizaje musical la ocupan quienes están debajo de las piernas de los mayores. En Quibdó esta imagen es permanente.

Cuando el discípulo es capaz de acompañar las canciones y se familiariza con el repertorio, comienza a desarrollar códigos concretos que lo diferencian de otros intérpretes. Dichos códigos se desarrollan en los matices musicales y en la improvisación. Por ejemplo, los clarineteros tienen grandes diferencias con las referencias estéticas de las escuelas "formales" o "académicas". En los escenarios informales los clarineteros "tradicionales" se caracterizan por reproducir unos sonidos altos, brillantes y estridentes. Como lo plantea Leonidas Valencia:

Ese músico así tiene muchos defectos frente a la música académica. Frente a la música tradicional no es defecto. Pelar nota no es 
defecto en chirimía (...). Tú das un la y sale un poquito más bajito (...). O pensé en tocar un la y toqué un si (...). Y se fue (...). Pero inmediatamente lo arregla. Eso es permitido. En la música leída no te permite, porque si es la tienes que tocar la. Si el músico toca muy estilizado el campesino se le marea [enfada]. Es que no le gusta que toque tan perfecto.

Los oyentes son quienes deciden quién es bueno y quién no. Los espacios domésticos tienen metodologías y rutas de aprendizaje concretas que no son fáciles. Posiblemente son más exigentes que las de la escuela formal pero en medio de su invisibilidad se pasan por alto e, inclusive, son deslegitimadas desde los cánones académicos, eurocéntricos y letrados (Carvalho, 2003; Miñana, I987; Small, 1980).

\section{La fiesta patronal: el san Pacho}

La fiesta patronal de san Francisco de Asís es el acontecimiento más importante del año para los músicos y para el pueblo en general. La "fiesta de san Pacho", como llaman cariñosamente los quibdoseños a su santo, es un complejo espacio simbólico en la vida religiosa, social y política del municipio. Durante un mes toda la comunidad se mueve entre la fe y las pasiones, la dicha y el jolgorio. Los límites entre lo sagrado y lo profano, lo "divino" y lo humano, la riqueza y la pobreza, se vuelven borrosos y difíciles de determinar y de entender. Por su alto contenido simbólico y por ser en sí misma un espacio de representación, en ella hay muchos elementos en juego. Las subjetividades se viven más intensamente, los valores se cuestionan, los roles sociales se invierten, los espacios se transforman y los tiempos se desdibujan. Como comunidad de práctica sin la que no funciona la fiesta, los músicos tienen un poder que los hace sentirse mucho más representados, observados, admirados pero también criticados. La fiesta, los desfiles y las procesiones son espacios concretos donde deben demostrar su virtuosismo y su capacidad de improvisación. En cada comparsa la gente se acerca al músico, le grita, le exige y "no se deja engañar". Cuándo un músico "no da la talla" rápidamente es reemplazado. En apariencia los escenarios musicales en Quibdó son eminentemente masculinos; las 
mujeres tienen otros roles dentro de la fiesta que no están por lo general relacionados con la ejecución instrumental ${ }^{19}$.

La resistencia física es un requisito fundamental. Leonidas Valencia plantea que en la fiesta los músicos se enfrentan a una especie de "selección natural”. Quibdó es uno de los puntos más calientes y húmedos del planeta;

I9. En las fiestas de san Pacho las mujeres están presentes en el baile de las comparsas y tienen la responsabilidad de que cada uno de los espacios funcione desde el punto de vista logístico. Ellas se encargan de organizar las procesiones, los desfiles, los cachés (trajes), los disfraces y la comida, y de cuidar que los músicos estén siempre presentes y que no les falte nada. llueve y hace sol; la temperatura puede pasar de $30^{\circ}$ a $19^{\circ}$ en pocos minutos. Esto demanda una resistencia física especial, sobre todo cuando los músicos cargan sus instrumentos y transpiran sin parar. Por otra parte, el desfile puede durar cinco o seis horas. Para muchos, el alcohol es una forma de resistir las inclemencias del clima, la poca consideración de los oyentes, el peso de los instrumentos, el cansancio físico y la larga trayectoria. Con la muestra de virtuosismo, el consumo de alcohol y la resistencia física, los músicos demuestran su hombría. Ser hombre, por tanto, es mostrar habilidad musical frente a un instrumento asumiendo todos los desafíos: tomar sin emborracharse y mostrar enormes músculos que respaldan una gran resistencia física, y probablemente sexual.

Además de la construcción de una "masculinidad" por parte de los músicos en la fiesta, en ella es posible ver también la construcción de una identidad étnica y racial. ¿Qué significa ser negro? ¿Por qué vivimos la fiesta como la vivimos? En palabras de Adanies Palacios:

Indudablemente es que esta fiesta está diseñada para negros. Es una constitución que los negros tenemos. Nosotros aguantamos cualquier fiesta del mundo. Porque es algo de verdad inexplicable aguantar seis horas con sol y lluvia, y luego en la noche aguantar la verbena otras seis horas.

La fiesta es, entonces, el lugar privilegiado para pensarse y pensar a los demás. ¿Qué tienen los chocoanos que no tiene el resto del mundo? Es una pregunta que surge al comprender que efectivamente en un espacio de representación -desfiles frente a un público, euforia, violencia, jolgorio, llanto y fe-como sujetos 
de allá o de acá, sacamos lo “mejor” o lo “peor” de nosotros ${ }^{20}$. Los discursos en torno a la idea de ser chocoano o afrodescendiente se nutren de comportamientos y elementos concretos de la fiesta para reafirmarse. Como lo plantea Daniel Mosquera en su investigación sobre la fiesta de san Pacho en Quibdó, esta cumple un rol fundamental en los procesos de construcción de identidad y en la politización del ser "afrocolombiano”. Así, la fiesta es un espacio fundamental para la reconstrucción de la memoria, la reinvención de la africanidad y la experimentación del cuerpo

20. La fiesta de san Pacho resume también, en alguna medida, la guerra y la violencia que se vive en la región. Quibdó vive una situación tensa que se agrava con el paso de los años por ser un municipio receptor del desplazamiento forzado, por los traumatismos y por los miedos que dejan los grupos armados. La fiesta no está al margen de esto. Por ejemplo, durante el rebulú, es decir la masa de gente que salta y baila desenfrenadamente al final de cada desfile en el san Pacho, los jóvenes salen y algunos actores aprovechan para hacer la llamada "limpieza social". De esta manera se mata a quienes se consideran "parias" en la sociedad. En la fiesta se vive la euforia, pero también una enorme tensión, porque nunca se sabe quién será el próximo en caer en esta "guerra de pandillas". como un lugar fundamental en el que residen las tensiones poscoloniales y donde yace un claro lenguaje de resistencia (Mosquera, 2004: 172, 175, 179).

En la fiesta los oyentes no escuchan pasivamente. Son activos, gritan, critican e incluso pueden arrebatar al músico su instrumento y reemplazarlo buscando una sonoridad más convincente. Por este motivo el músico debe congraciarse con la gente atendiendo sus peticiones y, sobre todo, expresar con su música caracteres y personalidades especiales: "formas de ser negro" que se asocian con un sonido juguetón y sincopado que identifique a la gente en medio de la improvisación, las estridencias, las disonancias y las discrepancias. Como lo señala Charles Keil (I994), la discrepancia es la característica que permite que la música se convierta en un vehículo peculiarmente poderoso en la conciencia y la acción participativa.

A pesar de la alta participación de toda la comunidad negra, en la fiesta existe una clara estratificación que termina reflejándose en las prácticas musicales. Hay entonces una especie de "chirimías de élite" y "chirimías de calle". Las primeras sólo salen de vez en cuando y son muy bien remuneradas, son pequeñas versiones de chirimías orquestadas o tradicionales que cuentan con un reconocimiento regional y nacional. No es del todo casual que estas chirimías estén compuestas y dirigidas por los ex alumnos del padre Isaac. Los "elegidos" del padre son los maestros más reconocidos de Quibdó e independientemente 
de si tienen o no mayor estatus económico, son "la élite" de la fiesta. La "chirimía de calle" es la que sale espontáneamente de los barrios y está conformada generalmente por jóvenes o por músicos aficionados. Se caracteriza por ser menos rigurosa en la ejecución de su repertorio, por su flexibilidad a la hora de afinar e interpretar los instrumentos y por involucrar temas alternativos al sumario tradicional.

La fiesta es entonces un espacio privilegiado de aprendizaje. Participar en ella es "lanzarse al ruedo". Al igual que en los espacios domésticos, hay una serie de formas o estrategias de aprendizaje que desde las esferas formales no se reconocen como "metodologías". Sin embargo, hay unos elementos y lógicas que resultan fundamentales para los músicos a la hora de salir al desfile y demostrar su capacidad de resistencia física, su valor y su virtuosismo.

\section{Educación “formal”: colegios y universidades}

LAS ESCUELAS Y LOS COLEGIOS SON OTROS ESCENARIOS FUNDAMENTALES DE educación musical en Quibdó. Los discípulos del padre Isaac terminaron enseñando allí y por eso muchos comportamientos, valores y metodologías de la escuela de la catedral se han mantenido vivos en esos ambientes de educación formal. En Quibdó no existe un departamento de música en la universidad o en los institutos de educación superior, carencia que obliga a muchos músicos a salir del municipio para ser considerados profesionales en el actual sistema de educación. A pesar de esto los músicos chocoanos son toda una escuela: la salsa en Colombia tiene el sello del Chocó y en las comunidades de práctica del departamento es posible aprender inclusive más que en los programas de formación superior. Cecilio Lozano cuenta su experiencia:

Estudié pedagogía musical en la Universidad Pedagógica Nacional. Pero entonces no me convencí. Yo quería hacer mucho más de eso sin perder mis tradiciones. Allá no se permite que el individuo toque lo de él. Los valores se los quieren mutilar a uno. Hay que aprender con base en lo que tú eres, las costumbres que tú tienes de allí te forman, allí te abres a las demás culturas (...) los mejores salsómanos han sido músicos de chirimía, los mejores salsómanos de Colombia y digo yo, me atrevo a decir de América del sur, han 
sido los chocoanos. Nosotros somos los que hemos fomentado la salsa acá. Ahí está Guayacán, Niche, todos han sido músicos de chirimía. Eso les dio margen al desarrollar lo que es la salsa y los máximos ponentes fueron alumnos del padre Isaac ${ }^{21}$.

Este testimonio muestra un conflicto entre la educación formal y la informal, conflicto resultado de la imposición de comportamientos y valores que se presentan en la educación formal como legitimadores de prácticas y comunidades para convertir a las personas en "sujetos modernos", con base en la valoración de unos saberes ajenos y la descontextualización

2I. Niche y Guayacán son dos agrupaciones emblemáticas de la salsa en Colombia. Jairo Varela y Alexis Lozano, sus directores, se formaron en la escuela del padre Isaac y luego se fueron a Cali, donde alcanzaron reconocimiento y fama nacional e internacional. del conocimiento. En los espacios formales de educación musical se valora la lecto-escritura así como unos repertorios y unas técnicas de interpretación que responden más a un canon europeo que a la tradición y a la música local. El maestro Heriberto Valencia, por ejemplo, montó el coro de la universidad Diego Luis Córdoba que interpreta "música litúrgica, música clásica, de Beethoven, tenemos una fantasía de Beethoven que es muy bonita a ocho voces". Esta utilización de formas "universales" y "ajenas" puede generar choques que se expresan más en el rechazo a métodos y a estilos de interpretación que en los discursos de los músicos. Teniendo en cuenta que en estas esferas se reafirman elementos culturales "propios" y "ajenos", en ellas hay también una lucha por otorgar sentido a saberes y conocimientos en los contextos inmediatos de la población. En este sentido, los espacios de educación formal pueden recontextualizar o descontextualizar el conocimiento.

En la escuela formal la escritura y la tradición oral como métodos se apoyan, se complementan, se contradicen o se excluyen. En las músicas negras tradicionales es común que la escritura sea insuficiente para representar lo que realmente pasa en el performance. Por tanto, la tradición oral y todo lo que ésta representa -imitación, gestos, ejemplos onomatopéyicos- es mucho más ilustrativa del aprendizaje de ciertos repertorios locales tradicionales. Pero si se toma el repertorio de una tradición "letrada y académica", las partituras son el vehículo privilegiado. El problema de legitimar unas formas sobre otras en la educación formal es que los métodos de calificación son 
mucho más "efectivos" y "objetivos" si se evalúa una "tradición letrada". Es decir: si la partitura dice la, el alumno debe tocar un la independientemente de su capacidad improvisadora, de su virtuosismo o de su histrionismo a la hora de interpretar el instrumento. Más allá de lo que un sistema curricular formal valore, legitime o privilegie, los alumnos son los que en últimas adoptan o no los contenidos "transmitidos". Las escuelas y los colegios son un medio privilegiado para el nacimiento de comunidades de práctica musicales, que toman y dejan los elementos aprendidos de una forma ecléctica y funcional. Combinan los viejos y los nuevos estilos y tratan de "sacar partido" a los contenidos institucionales.

Evidentemente, los espacios expuestos no son los únicos que albergan comunidades de práctica. Existen otros ámbitos en los que encontramos una serie de dinámicas donde se negocian la legitimidad y la pertinencia de métodos y teorías musicales. Las orquestas de salsa, los grupos de rap y reggaetón, los talleres institucionales e informales en Quibdó y en las grandes ciudades son espacios fundamentales para la construcción de modelos pedagógicos alrededor de la vida musical de la ciudad. Los festivales y encuentros folklóricos, por ejemplo, han sido desde la década de 1960 escenarios fundamentales de la consolidación de un discurso formativo en los repertorios locales del Chocó. También hay comunidades de práctica que no son tan evidentes como las que se generan a partir del consumo musical radiofónico y discográfico o las que se construyen en los lugares de ocio donde no necesariamente hay un contexto barrial o doméstico vinculado. En la actualidad muchos de estos grupos se construyen y fortalecen en los espacios que brindan el mercado y los medios de comunicación e información como internet y los canales locales de televisión.

Este nuevo panorama adquiere otros matices -en el fondo no tan nuevos- con el surgimientos de dinámicas geopolíticas que, como veremos, trascienden la lógica de lo local, lo nacional y lo internacional y se manifiestan con la presencia de las agencias de cooperación, las organizaciones no gubernamentales y los movimientos sociales. 


\section{Nuevos Espacios de EDUCACIÓN MUSICAL}

OS ESCENARIOS QUE EMERGEN CON LOS NUEVOS MEDIOS DE COMUNICACIÓN y las lógicas de consumo musical como las comunidades virLtuales, y los grupos de reggaetón y hip hop, se entrelazan íntimamente con los espacios formales e informales que he trabajado en este artículo. Además se relacionan con lo que he denominado "nuevos espacios de educación musical”: "espacios diplomáticos para procesos de paz" y "espacios de base para el fortalecimiento de identidades" 22 . Aunque son absolutamente heterogéneos y estas categorías rayan inevitablemente en lo abstracto, es interesante ver qué tanto las políticas de la escena global internacional como las de la escena local -que también responden a dinámicas transnacionales-comparten una concepción común en la cual la música es un espacio fundamental no sólo de expresión sino también de formación de subjetividades. Las ONG -que en principio representan a la sociedad

22. Alejandro Cifuentes hace un estudio interesante sobre los intercambios entre los músicos de Bogotá y los del Chocó. Los talleres, los festivales y las tarimas en la ciudad configuran otro espacio importante de enseñanza y aprendizaje y en ellos es posible ver estrategias de empoderamiento por parte de los músicos locales ante los jóvenes músicos urbanos (Cifuentes, 2005). civil o iniciativas privadas- no tienen los mismos intereses de las embajadas o los programas derivados de las políticas culturales nacionales. En el seno de ellas subyacen criterios, modos de actuar e intenciones disímiles. Cada uno de nuevos ámbitos de educación artística presenta matices que pueden ser vistos en las estructuras metodológicas, en los contenidos pedagógicos y en la forma como integran o no las estrategias y los conocimientos locales.

Una mirada atenta a los diferentes espacios que emergen en la escena de formación musical de Quibdó -y la escena artística y política en general- permite ver que son contextos que se nutren de las dinámicas locales y son contextos transversales, es decir, se comunican y afectan todos los espacios de educación musical. Además, estos escenarios comparten una cierta capacidad para instrumentalizar la música con fines políticos, terapeúticos o demagógicos. 


\section{EsPACIOS DIPLOMÁTICOS PARA PROCESOS DE PAZ}

Clo OMO SI LA HISTORIA SE REPITIERA, SI HACE POCO MENOS DE CIEN AÑOS a Quibdó estaban llegando por el Atrato los claretianos para liberar a las comunidades negras e indígenas de su "pecado original" 23 e implantarles "La Fe", ahora estamos ante movimientos políticos internacionales que vienen a salvar a los fieles de los destrozos del capitalismo voraz y de la guerra. Se trata de dinámicas transnacionales en las que las relaciones "norte-sur"24 se establecen mediante formas de intervención como planes de desarrollo estatales o programas de ONG, embajadas y fundaciones, y presentan matices cuando los países objeto de la intervención como Colombia, sufren las consecuencias de la violencia y el desplazamient ${ }^{25}$. Muchos de estos programas han

23. Los espacios de educación musical por parte de sectores católicos durante el siglo diecinueve pueden traer a cuestas formas, imágenes, comportamientos y mecanismos de una historia colonial. Las misiones católicas coloniales llevaron a cabo la tarea de adoctrinamiento y enseñanza en la población negra con el convencimiento absoluto de que todo lo proveniente de África era primitivo, pagano, salvaje e impuro. Por este motivo, las misiones se vieron en la obligación de castigar esta herencia e imponer como modelo ejemplar la conducta y sabiduría del hombre blanco. Para profundizar en la religiosidad y las formas de resistencia de los esclavos africanos véase Maya (I996: 29).

24. Es decir, las relaciones entre los países "desarrollados" y los países "sub-desarrollados" o "en vía de desarrollo".

25. Para mayor información sobre la situación que viven las comunidades negras e indígenas en la actualidad en el Pacífico colombiano, se recomienda visitar las páginas web del Proceso de Comunidades Negras:http://www.renacientes. org/index.php; ; Etnias de Colombia: http://www. etniasdecolombia.org/index.asp; Impacto: http:// www.impacto2.com/Editorial.htm; http://www. choco7dias.vze.com/; Instituto de Investigaciones Ambientales del Pacífico: http://www.iiap.org.co/; y del Colectivo de Organizaciones del Pacífico: http://www.colectivopacificodarien.org/? $\mathrm{id}=6$. sido de gran ayuda para el fortalecimiento de grupos sociales en riesgo y para la denuncia de la vulnerabilidad de sus derechos como ciudadanos. Sin embargo, es fundamental no olvidar que su carácter internacional es fuertemente cuestionado por algunos líderes y movimientos sociales que -aunque por lo general demandan la atención y los recursos ofrecidos- no desconocen que en medio de programas de cooperación pueden existir serias intenciones de colonización no solamente económica sino también política e ideológica.

El Chocó, como una zona inmensamente rica por su biodiversidad y sus minas, ha sido desde la conquista un territorio explotado por empresas nacionales e internacionales. Como lo señala González Escobar: “con la abolición de la esclavitud no finalizan de por sí las relaciones señoriales. Pero con la nueva dinámica mercantil producto de la exportación se generó otro tipo de relaciones, como la transición al trabajo asalariado" (González 
Volumen 44 (I), enero-junio 2008

Escobar, 2003: 64, 65). A una realidad de exclusión, discriminación y discursos hegemónicos que han sostenido que lo "afro" y lo "indígena" son un obstáculo para la proyección de un estado moderno (Cunin, 2003: 2I-78; Restrepo, 2007: 43-7I), se suma una realidad de violencia, recrudecida desde hace quince años. Rojas y Restrepo resumen esta situación en la introducción del libro Conflicto e (in)visibilidad. Retos en los estudios de la gente negra en Colombia (2004: 19):

Como en cualquiera de los rincones del país, en la región del Pacífico la generalización de la confrontación armada, el posicionamiento del narcotráfico, la intromisión de los intereses del modelo de desarrollo capitalista y la existencia de unas instituciones estatales ampliamente deslegitimadas, han tenido efectos desestructurantes (sic) en los tejidos sociales y agendas de las poblaciones locales. Sin embargo, tal vez en el Pacífico estos efectos han sido más perversos en la medida que revierten un claro proceso de empoderamiento de las poblaciones negras en la reivindicación de sus derechos territoriales y culturales como grupo étnico. Este paradigmático proceso organizativo de las comunidades negras del Pacífico logró concertar exitosamente con el estado un marco legislativo, que sentó las bases no sólo para un régimen de propiedad colectivo que cubre gran parte de la región, sino que también definía modalidades de poder local que perfilaban a las organizaciones étnico-territoriales como interlocutoras legítimas en las decisiones que involucran a sus comunidades. Esta dimensión étnica de las dinámicas de la guerra y violencia en Colombia, ejemplificada claramente en la región del Pacífico, ha sido soslayada en las narrativas y análisis que circulan en los medios masivos de comunicación (sic) en el país y en el exterior.

Sostenidos por el discurso de la paz, algunos programas de agencias nacionales e internacionales adoptan la educación musical como un instrumento para alejar a los niños del conflicto y la violencia. Existen escuelas no formales de música en Quibdó como Mama U y Batuta -que funcionan con dineros provenientes de España, Estados Unidos, Holanda, Japón-, la Fundación Pies Descalzos -cuya cabeza más visible es la cantante Shakira-y otras ONG de procedencia nacional e internacional. Estas dos escuelas son las más visibles en Quibdó ${ }^{26}$. Mama U pertenece a la diócesis de Quibdó y funciona con los fondos de la iglesia

26. El Centro Cultural Mama U trabaja en formación musical con cincuenta niños; Batuta, por su parte, ofrece la formación a alrededor de seiscientos niños que hacen parte de los Centros de atención a desplazados como Pies Descalzos, Santana y La Victoria. El Plan nacional de música para la convivencia, a su vez, está enfocado a la formación de formadores de 
directores de escuela de dieciocho municipios en los cuales se imparte educación musical a un promedio de cuarenta y cinco niños.

27. El PNMC apoya las prácticas de bandas, coros, músicas tradicionales u orquestas en los municipios de país, priorizando una práctica en cada uno de ellos. En el caso del Chocó, el Plan delega el movimiento orquestal a Batuta y temporalmente ha decidido no fortalecer la práctica coral hasta que no se presente la metodología adecuada para trabajar las particularidades de las voces negras. Por tanto, en este departamento el plan se encamina hacia los movimientos de banda y las músicas tradicionales. católica y con donaciones internacionales, principalmente del gobierno español; Batuta es un organismo mixto que combina dineros públicos y privados nacionales e internacionales; y aunque el Plan nacional de música para la convivencia (PNMC) depende organizativa y financieramente del Ministerio de Cultura, cuenta también con dinero estadounidense para su dotación instrumental. Los tres proyectos están dirigidos a la educación musical de niños de los barrios marginales en situación de riesgo -drogas o violencia- por su condición de pobreza y desplazamiento. En Mama U los niños aprenden interpretación de instrumentos de viento; en Batuta el formato es orquestal: cuerdas, vientos y percusión; más de doscientos niños aprenden lecto-escritura musical. En el PNMC las prácticas que se priorizan son las bandas y las músicas tradicionales $^{27}$, y aun cuando está en su primera fase, durante la cual se limita a formar a los maestros de música de los municipios, ya ha generado una visibilidad notoria en el panorama nacional.

Durante mi trabajo de campo en 2006 me percaté de que los maestros de música de Mama U eran los mismos de Batuta, del Plan nacional de música para la convivencia del Ministerio de Cultura y de la banda municipal San Francisco de Asís. Todos ellos, antiguos alumnos de la escuela del padre Isaac en la Catedral. Esto resulta interesante porque nos muestra que a pesar de que fomentan la educación musical bajo un discurso abiertamente instrumental que responde a necesidades y lineamientos de escenarios internacionales de cooperación, en el fondo los métodos pedagógicos pueden ser los mismos de los escenarios tradicionales de educación musical.

El documento de Estrategia de cultura y desarrollo de la Cooperación Española, afirma que:

El plan director de la cooperación española 2005-2008 (Plan director 2005-2008) por primera vez establece como objetivo general aumentar las capacidades culturales de los individuos y las sociedades en las que se interviene, para que aquellos puedan ejercer con autonomía 
su libertad cultural, así como para aprovechar las posibilidades que ofrece la acción cultural en el exterior como factor de desarrollo (2007: 9).

Los maestros que hacen parte de los centros educativos y culturales dependientes de la cooperación internacional se apropian de este discurso, que es fortalecido con el discurso que ya se manejaba en la escuela de música católica. En palabras del profesor de música César Córdoba:

Ante la situación social que se atraviesa en nuestro medio, de pandillas, de prostitución, de drogadicción, de cosas que están socavando principalmente a la familia como principal estructura de nuestra sociedad y en donde se han perdido tantos valores, hemos considerado la música como la posibilidad de brindarles algo diferente a los niños. La música como un factor resocializador, como un factor formador y como una opción de vida. Me interesa más formar a la persona que no al músico. Si yo tengo persona tengo músico, si no formo persona no tengo músico.

En la enseñanza musical que se imparte en los espacios diplomáticos para procesos de paz y su encuentro con metodologías, teorías y contenidos propios de las comunidades de práctica locales, cabe preguntarnos: ¿más allá de la inserción de un nuevo discurso y vocabulario en el que encontramos términos como "gestor", "tejido social”, "identidad”, "resocialización”, "patrimonio", "salvaguarda”, etcétera, qué cambios radicales afrontan los contextos de educación musical, sus contenidos y metodologías? Esta pregunta va acompañada de otras que merecen un sesudo análisis etnográfico: ¿de qué manera se privilegian estas metodologías y contenidos? ¿Cuál es el uso que le dan los niños a lo aprendido en sus contextos domésticos? ¿Cuál la valoración que le dan a la educación musical las familias de estos niños? ¿Cómo se diferencian los niños que asisten a estos centros de los que no lo hacen?

En los espacios para procesos de paz he incluido a organizaciones con características y políticas diversas que tienen en común la idea de que la cultura y la educación musical configuran un escenario privilegiado para la construcción de sujetos sociales pacíficos en un contexto de guerra y pobreza. Como señala Ana María Ochoa, partiendo del planteamiento de George Yúdice, en el mundo globalizado la fractura del sentido clásico de la credibilidad en la política ha cedido a la cultura el lugar de lo político: 
La idea de que la música sirve para solucionar los problemas de la sociedad y la tendencia a instrumentalizar su sentido para causas socio-políticas de solución a la fractura del orden social no es, ni mucho menos, nueva (...). Lo nuevo por tanto no es la tendencia a postular lo musical como aquello que cohesiona lo social, sino la manera como dicha instrumentalización ha proliferado de manera simultánea como episteme de lo musical a través de una gran variedad de espacios intelectuales, de ideologías políticas, de prácticas musicales y de espacios públicos y por tanto adquiere el tenor de una verdad asumida sobre el sentido y valor de lo musical (Ochoa, 2006: I).

La tendencia a considerar la cultura como un recurso está presente también en lo que denomino "espacios y organizaciones de base para la construcción y el fortalecimiento de identidades”, que a su vez, sin duda, han adoptado prácticas y políticas culturales de los “espacios diplomáticos para procesos de paz”. Estos espacios y organizaciones de base responden a procesos de lucha por el respeto y la visibilidad de las comunidades negras e indígenas en el panorama nacional ${ }^{28}$. La música se ha convertido en una herramienta eficaz en la construcción de un discurso sobre entidades propias y en la legitimación de una "ancestralidad" africana que hace a los negros di-

28. Con la ley 70 de I993, que se expidió gracias a la Constitución política de I99I, las comunidades negras pudieron acceder a la titulación colectiva de territorios habitados ancestralmente pero que se consideraban baldíos, y pudieron aspirar a la construcción de políticas educativas, sociales y económicas que reconocían su condición de "minoría" étnica y sus particularidades culturales. Dicho proceso se tradujo en un afán por la búsqueda de elementos que fortalecieran un discurso propio sobre la identidad cultural, la diferencia y el derecho al territorio, que se ha sustentado en ámbitos discursivos complejos como la conservación de la biodiversidad en el Pacífico, la autenticidad cultural y la historia. Para un análisis y una historia crítica de los movimientos sociales en el Pacífico colombiano véase Restrepo (2005: 215).

29. Parto del planteamiento de Gramsci en el cual la hegemonía es la influencia en la sociedad de un sistema de valores, actitudes, creencias y moralidad que tiene el efecto de mantener el statu quo dentro de las relaciones de poder. La hegemonía es, en este sentido, un "principio organizativo" difundido por procesos de socialización en cada área del diario vivir (Boggs, I976). ferentes del resto de la población mestiza y, por tanto, sujeto de derechos especiales. Este proceso reivindicativo se ha dado en las organizaciones de base, en barrios y veredas, y en las organizaciones de jóvenes, mujeres, indígenas o campesinos (Arocha, I996; Escobar, 1998; Hoffmann, 2002; Restrepo, 2003). De esta manera, los movimientos sociales seleccionan y en algunos casos generan elementos culturales considerados idiosincrásicos como una estrategia de legitimación frente a un sistema hegemónico ${ }^{29}$. Esto no quiere decir que para los sujetos y las comunidades estos elementos culturales no cumplan un papel 
fundamental en la cohesión y el reconocimiento social ${ }^{30}$. La función de la educación musical en el panorama de las organizaciones de base requiere un análisis de tipo etnográfico que en un futuro permita comprender su relación con los espacios locales de educación aquí analizados y con los escenarios nacionales e internacionales que hacen de la música un instrumento complementario a los discursos de paz, sostenibilidad y desarrollo ${ }^{31}$.

\section{CONSIDERACIONES FINALES}

A VIDA MUSICAL DE UN PUEBLO SE CONSTRUYE EN COMUNIDADES DE PRÁCTICA que comparten repertorios, identidades y competencias a partir -de aprendizajes continuos (Wenger, 200I). Hay una vida musical que acontece con especificidad, complejidad y flexibilidad. La especificidad permite la identificación de repertorios, competencias, valores o comportamientos particulares de unas comunidades frente a otras. La flexibilidad indica que no hay cánones rígidos y determinados desde los que se construyen los conocimientos

\footnotetext{
30. Michael Birenbaum retoma el concepto de "biodiversidad" y plantea el término de "etnodiversidad" para explicar las prácticas y los discursos de los movimientos sociales: "La etnodiversidad tiene la posibilidad de ser un espacio de esperanza; los logros del movimiento afro en torno a los derechos sobre territorio colectivo de algunas comunidades, el reconocimiento oficial de la cultura afrocolombiana, la repentina visibilización/audibilización de esa cultura, los incipientes vínculos con grupos negros en otros países y la valoración oficial de las contribuciones de las negritudes a la sociedad y cultura colombianas son algunos de los frutos del aprovechamiento de los vínculos que la etnodiversidad posibilita entre las esferas locales y espacios más amplios (...). Lo preocupante es que los espacios ganados parecen ser bastante circunscritos. El hecho de que las versiones éticas de la cultura afro suelan moldear las versiones émicas en su imagen podría significar que los actores locales tienen que formular sus proyectos culturales dentro de patrones impuestos desde afuera (...). Así notamos que los planteamientos alternativos siempre tienen que forrarse en las lógicas occidentales, como son el historicismo y la espectacularización. Esto es porque al fin y al cabo, la etnodiversidad se dirige al consumidor o funcionario cosmopolita, que contempla la gama de otredades desde su asiento panóptico en la cultura occidental, más que hacia aquellos 'otros' que encuentran sus mundos culturales repentinamente inmersos en la estructura moderna que es la etnodiversidad" (2005: 36).

31. Al igual que los "espacios diplomáticos para procesos de paz", los "espacios de base para el fortalecimiento de identidades" nos invitan a pensar de qué manera se trazan nuevas rutas, mecanismos y estrategias en las formas de aprendizaje de las comunidades de práctica y qué comportamientos, valores y metodologías permanecen. Además, cabe preguntar al respecto de dichos espacios: ટ̇modelan estos movimientos sociales "sujetos" diferentes a los que se forman musicalmente en otro tipo de espacios? ¿Cómo se presentan las relaciones entre "gestores culturales", alumnos y maestros? ¿De qué manera se asimilan los conflictos sociales en estos espacios? Y, żqué lectura de ellos tienen los demás habitantes de Quibdó?
} 
musicales, lo que no significa una especie de permisividad. Por el contrario, las comunidades de práctica se consolidan en contextos de micropolítica y de discursos hegemónicos en los que la libertad para asumir ciertas maneras de ser es cuestionada, obstaculizada o vetada de forma abierta o enmascarada. Y la complejidad es aquella característica que nos explica la imposibilidad de trazar límites entre distintos escenarios musicales. Por ejemplo, la imposibilidad de comprender hasta dónde se constituye la fiesta como espacio de educación y qué papel tienen en ella las comunidades de práctica de los espacios domésticos o de la banda de San Francisco de Asís. Los lugares, los conocimientos y las técnicas traspasan los escenarios de educación musical y se yuxtaponen, generando una enorme riqueza y una gran complejidad en los códigos concretos que se manifiestan en cada uno de estos.

En los procesos de aprendizaje musical hay relaciones de poder dinámicas y complejas. En el caso de Quibdó las misiones religiosas legitimaron una serie de valores éticos y estéticos por medio de la educación musical y a costa de fuertes estigmatizaciones de las prácticas musicales locales. Las comunidades de práctica musical de Quibdó han ejercido procesos de resistencia mediante la reafirmación y la defensa de valores locales; sin embargo, la resistencia es compleja y muchas veces contradictoria. Por ejemplo, la mayoría de músicos chocoanos defiende abiertamente la implantación de valores ajenos por parte de sectores dominantes como la iglesia.

El estudio de las comunidades de práctica y los espacios de aprendizaje musical en Quibdó nos ayuda a entender las complejas relaciones entre educación y poder. Las comunidades exponen una interdependencia entre los contextos formales e informales; la comunidad se apropia de unos conocimientos específicos que le son dados en contextos de poder y, a la vez, los toma y los usa de una manera práctica y ecléctica. Para los chocoanos leer y escribir música es importante como herramienta para recordar, grabar y comunicar, pero no lo es todo. El eclecticismo con el que utilizan los conocimientos adquiridos en un contexto de dominación es una forma de reafirmación de unos valores locales. Los repertorios musicales no se trasladan de un sector a otro de forma directa, unidireccional y automática. No hay unos saberes, valores o comportamientos que se pasan de adultos a niños, de profesor a alumno, de padres a hijos, de clases altas a subordinados, de letrados a iletrados o de autoridades políticas 
y eclesiásticas a un "pueblo”. El repertorio musical se aprende en medio de un acontecer y los contenidos pedagógicos asumen caminos diversos.

Después de esta mirada panorámica a los diferentes contextos $\mathrm{y}$ ambientes en los que se comparte y fortalece el conocimiento musical, nos encontramos con que las fronteras entre unos y otros son complejas y difusas. La preparación musical que recibieron los alumnos del padre Isaac en la catedral fue utilizada por estos para sus prácticas domésticas y festivas. Por otra parte, la educación en espacios formales siempre se ha quedado corta frente a la capacidad creativa de los niños y jóvenes que nutren estos espacios con el conocimiento que recogen de sus pares en los ambientes cotidianos del barrio y la calle. Esta vivencia creativa y sus mecanismos de expresión se encuentran vivos y han sido apropiados por nuevos actores y en nuevos escenarios como los movimientos sociales, las ONG, las embajadas y las fundaciones.

Los nuevos espacios de enseñanza en Quibdó nos recuerdan que la vida musical de un pueblo nunca está exenta de avatares sociales y políticos. El mapa geopolítico mundial, las relaciones norte-sur, la nueva configuración de redes y los proyectos asistencialistas llegan a lo más profundo de los tejidos sociales. Aparentemente estos escenarios son nuevos. Sin embargo, en ellos hay una continuidad en los roles, los métodos, los contenidos y los valores, que se esconde bajo el velo de nuevos discursos de "desarrollo", "paz” y "modernidad”, y bajo la proclamación abierta de la enseñanza musical como un escenario y un recurso político para el cambio social.

\section{BibliografíA}

Arocha, JAIME. I996. "Afrogénesis, eurogénesis y convivencia interétnica”. En Arturo Escobar y Álvaro Pedrosa (eds.). Pacífico: ¿Desarrollo o diversidad? Estado, capital y movimientos sociales en el Pacífico colombiano. Cerec. Bogotá.

Béhague, Gerard. I999. “Latin America”. En Helen Myers (ed.). Ethnomusicology: Historical and regional studies. W.W. Norton \& Company. Nueva York.

Bermúdez, EgBerto. 2000. Historia de la música en Santafé y Bogotá I538I938. Fvndación de Mvsica. Bogotá. 
Bermúdez, Egberto. 1986. “Aguacerito Llové”. En Música tradicional y popular colombiana. Volumen 9. Procultura. Bogotá.

Birenbaum, MichaEL. 2005. "Música afropacífica y autenticidad identitaria en la época de la etnodiversidad”. Ponencia para la mesa Música y sociedad. Congreso nacional de antropología, Santa Fe de Antioquia, Colombia. Texto inédito.

Blacking, JoHn. I973. How musical is man? University of Washington Press. Seattle.

Boggs, Carl. 1976 Gramsci's Marxism. Pluto Press. Londres. . I967. Venda Children's Songs. Witwatersrand University Press. Johanesburgo.

Campbell, Patricia Shehan. I998. Songs in their heads. Music and its meaning in children's lives. Oxford University Press. Nueva York.

Carvalho, José Jorge. 2003. "La etnomusicología en tiempos de canibalismo musical. Una reflexión a partir de las tradiciones musicales afroamericanas”. Revista Transcultural. 7, diciembre. Página web:http:/www.sibertrans.com/trans7/carvalho.htm. Fecha de consulta: abril de 2007.

Cifuentes, AlejAndro. 2005. "Pa' que se le quite la arrechera. Trayectos de aprendizaje de la chirimía chocoana”. Monografía de grado. Facultad de ciencias humanas. Departamento de antropología. Universidad Nacional de Colombia.

Cox, Gordon. 2006. "La investigación histórica en educación musical: influencias de las ideas sobre la infancia, de las iglesias y de las escuelas". Revista Electrónica Complutense de Investigación en Educación Musical. 3 (I). http:/www.ucm.es/info/reciem/index.htm. Fecha de consulta: mayo de 2007.

Cunin, EuISABETH. 2003. Identidades a flor de piel. Lo negro entre apariencias y pertenencias: categorías raciales y mestizaje en Cartagena (Colombia). Instituto Colombiano de Antropología e Historia-Universidad de los Andes-Instituto Francés de Estudios Andinos-Observatorio del Caribe Colombiano. Bogotá.

EsCOBAR, ARTURO. I998. "Política, cultura y biodiversidad: estado, capital y movimientos sociales en el Pacífico colombiano”. En María Victoria Uribe y Eduardo Restrepo (eds). Antropología en la modernidad. ICAN-Colcultura. Bogotá.

Fernández Poncela, Ana M. 2005. Canción infantil: discurso y mensaje. Anthropos. Barcelona.

Foucault, Michel. I983. "El sujeto y el poder". Revista de Ciencias Sociales. I2. 
GONZÁLEZ EsCOBAR, LuIS FERNANDO. 2003. Quibdó: contexto histórico, desarrollo urbano y patrimonio arquitectónico. Instituto de Investigaciones Ambientales del Pacífico (IIAP).

HofFmann, Odile. 2002. "Conflictos territoriales y territorialidad negra el caso de las comunidades afrocolombianas”. En Claudia Mosquera, Mauricio Pardo y Odile Hoffmann (eds.). Afrodescendientes en las Américas: trayectorias sociales e identitarias. Universidad Nacional de Colombia-ICANH-IRD-ILAS. Bogotá.

Ingold, Tim. I986. Evolution and social life. Cambridge University Press.

Kartomi, MARGAReth. I99I. "Musical improvisations by childrens at play". The World of Music. 33 (3). . I980. "Childlikeness in play songs -A case study among the Pitjantjara at Yalata, South Australia”. Miscellanea Musicologica. II.

KeIl, CharLes. 1994. "Participatory discrepancies and the power of music". en Charles Keil y Steven Feld. Music Grooves. University of Chicago Press. Chicago.

LAVE, JeAn y EtiEnne Wenger. I99i. Situated learning: Legitimate peripheral participation. Cambridge University Press. Nueva York.

List, George. 1989. "Colombia. Folk music”. En Stanley Sadie (ed.). The new grove dictionary of music and musicians. Vol. 4. McMillan Publishers.

Marsh, Kathryn. I995. "Children's singing games: Composition in the Play Ground”. Research Studies in Music Education. 42.

Maya, LuZ AdrianA. I996. "África: legados espirituales en la Nueva Granada, siglo XVII”. Historia Crítica. I2.

MerRIAm, Alan. I964. The anthropology of music. Northwestern University Press.

MinKs, AmAnDA. 2002. "From children's songs to expressive practices: Old and new directions in the ethnomusicological study of children". Ethnomusicology. Journal of the Society for Ethnomusicology. 46 (3). Fall.

Miñana Blasco, Carlos. 2005. "Bajo las piernas de los mayores”. Mesa de trabajo Música y sociedad. Congreso Colombiano de Antropología. Santa Fe de Antioquia.

. I987. "Músicas y métodos pedagógicos, algunas tesis y su génesis". A Contratiempo. Octubre.

NetTl, Bruno. 2004. "Últimas tendencias de la etnomusicología”. En Francisco Cruces y otros (eds.). Las culturas musicales, lecturas de etnomusicología. Trotta. 
NetTL, BRuno. 1983. The study of ethnomusicology. University of Illinois Press. Urbana.

NetTl, Bruno y Gerard BéHague. I973. "Música folklórica afroamericana en Norteamérica y América Latina”. En Bruno Nettl (ed.). Música folklórica y tradicional de los continentes occidentales. Alianza Editorial. Madrid.

Nketia, J.H. KWABENA. I99I. "Music and cultural policy in contemporary Africa”. En Baumann (ed.). Music in the dialogue of cultures: Traditional music and cultural policy. International Institute for Comparative Music Studies and Documentation. Berlín.

OchOA, Ana María, 2006. "A manera de Introducción: la materialidad de lo musical y su relación con la violencia”. Revista Transcultura. http:/ www.sibetrans.com/trans/transio/ochoa.htm. Fecha de consulta: enero de 2008.

Pardo Tovar, Andrés y Jesús Pinzón. I96r. "Rítmica y melódica del folclor chocoano”. Conservatorio Nacional de Música-Centro de Estudios Folclóricos y Musicales-Universidad Nacional de Colombia. Bogotá.

Restrepo, Eduardo. 2007. “Imágenes del 'negro' y nociones de raza en Colombia a principios del siglo XX”. Revista de Estudios Sociales. 20.

. 2005. "Movimientos sociales afro y políticas de identidad en Colombia y Ecuador”. En Henry Bernal et al. Siete cátedras para la integración. Serie La universidad y los procesos de integración social. Convenio Andrés Bello. Bogotá (Con Catherine Walsh y Edizón León).

. 2003. "Entre arácnidas, deidades y leones africanos". Tabula Rasa. Revista de Humanidades. I.

Restrepo, EduARdo y Axel Rojas. 2004. Conflicto e (in)visibilidad: retos de los estudios de la gente negra en Colombia. Editorial Universidad del Cauca. Popayán.

Rogoff, Barbara. 1989. Apprenticeship in thinking: Cognitive development in social context. Oxford University Press.

Small, Christopher. I980 (I989). Música. Sociedad. Educación. Alianza Editorial. Madrid.

VALENCIA, LEONIDAs. 2006. La socialidad funcional de las músicas y los bailes de los afrodescendientes del Pacífico colombiano. Asinch. Quibdó.

Wade, Peter. 2002. “Identidad”. En Margarita Serje, María Cristina Suaza y Roberto Pineda (eds.). Palabras para desarmar: una mirada crítica al vocabulario del reconocimiento cultural. Instituto Colombiano de Antropología. Bogotá. 
Wade, Peter. 1997. Gente negra. Nación mestiza: dinámicas de las identidades raciales en Colombia. Universidad de Antioquia-ICAN-Siglo del Hombre Editores-Uniandes. Bogotá.

Wenger, E. 200I. Comunidades de práctica. Paidós. Barcelona.

Wertsch, J. V. I99I. Voices of the mind: A sociocultural approach to mediated action. Harvard University Press. Cambridge, MA.

YÚDICE, GEORGE. 2003. The expediency of culture. Duke University Press. Duke.

ESTRATEGIA DE CULTURA Y DESARROLLO DE LA COOPERACIÓN ESPAÑOLA. 2007. Ministerio de Asuntos Exteriores y de Cooperación-Secretaría de Estado de Cooperación Internacional-Dirección General de Planificación y Evaluación de Políticas para el Desarrollo. 